\title{
Giant atypical lymphoid hyperplasia of the colon
}

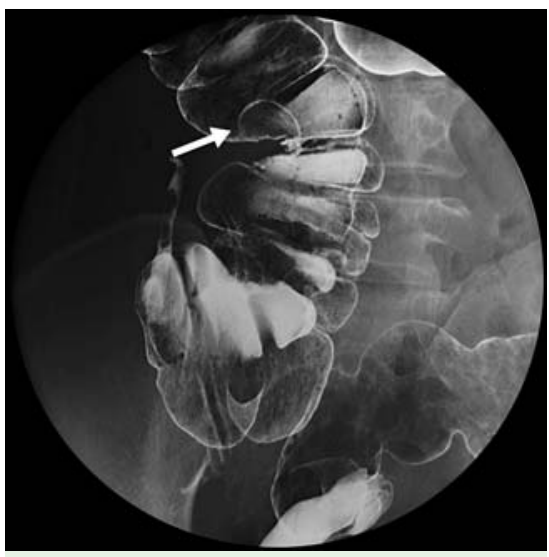

Fig. 1 Double-contrast barium study disclosed a mass of approximately $2 \times 3 \mathrm{~cm}$ (arrow) in the ascending colon.

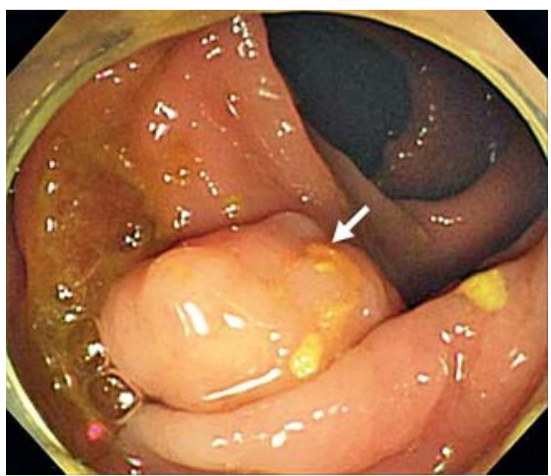

Fig. 3 Colonoscopy revealed one polypoid mass (arrow) in the ascending colon.

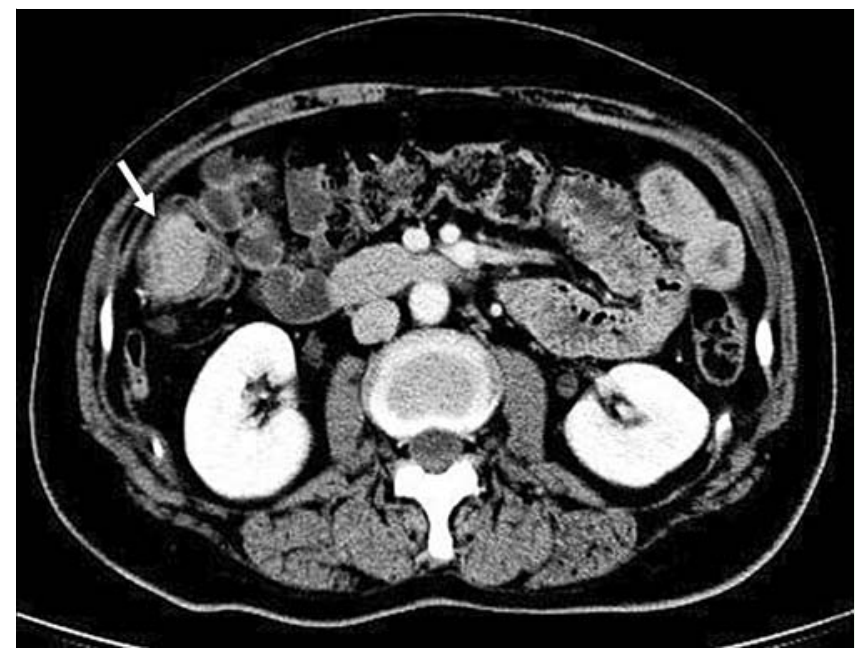

Fig. 2 Abdominal computed tomography (CT) showed one mass (arrow) in the ascending colon.

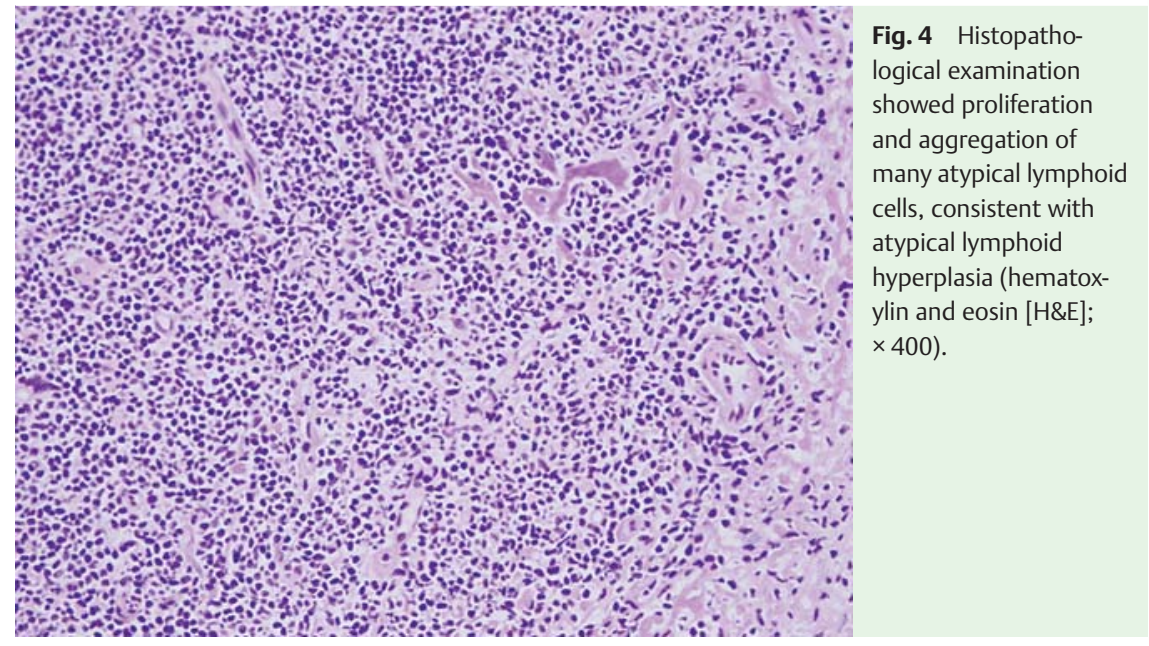

Endoscopic mucosal resection was accordingly performed. Histopathological examination showed proliferation and aggregation of many atypical lymphoid cells, consistent with atypical lymphoid hyperplasia ( Fig. 4).

The woman underwent colonoscopy 3 months later, which revealed that the mucosa of the lesion site had healed well. Atypical lymphoid hyperplasia is a condition usually related to an underlying immune dysregulation, or a reactive change to various inciting antigens or irritating stimuli [1-4]. To our knowledge, this is the first reported case of polyp-like atypical lymphoid hyperplasia in the colon; this may be considered a pre-lymphomatous state, and close follow-up is recommended $[4,5]$.

Competing interests: None

Endoscopy_UCTN_Code_CCL_1AD_2AC 
W.-C. Huang ${ }^{1}$, T.-Y. Hsieh ${ }^{1}$, H.-C. Chu ${ }^{1}$, T.-K. Chao ${ }^{2}$, T.-Y. Huang ${ }^{1}$

1 Division of Gastroenterology, Department of Internal Medicine, Tri-Service General Hospital, National Defense Medical Center, Taipei, Taiwan

2 Department of Pathology, Tri-Service General Hospital, National Defense Medical Center, Taipei, Taiwan

\section{References}

1 Crowson AN, Magro CM. Antidepressant therapy. A possible cause of atypical cutaneous lymphoid hyperplasia. Arch Dermatol 1995; 131: 925 - 929

2 Tanahashi T, Tatsumi Y, Sawai $N$ et al. Regression of atypical lymphoid hyperplasia after eradication of Helicobacter pylori. J Gastroenterol 1997; 32: 543-547

3 Viraben R, Lamant L, Brousset P. Losartanassociated atypical cutaneous lymphoid hyperplasia. Lancet 1997; 350: 1366

4 Krauss E, Konturek P, Maiss J et al. Clinical significance of lymphoid hyperplasia of the lower gastrointestinal tract. Endoscopy 2010; 42: 334-337

5 Takano Y, Kato Y, Sugano H. Histopathological and immunohistochemical study of atypical lymphoid hyperplasia and benign lymphoid hyperplasia of the stomach. Jpn J Cancer Res 1992; 83: 288-293

\section{Bibliography}

Dol $10.1055 / \mathrm{s}-0030-1255691$

Endoscopy 2010; 42: E195 - E196

(c) Georg Thieme Verlag KG Stuttgart · New York . ISSN 0013-726X

\section{Corresponding author}

\section{T.-Y. Huang, MD, PhD}

Division of Gastroenterology

Department of Internal Medicine Tri-Service General Hospital

National Defense Medical Center 325 Cheng-Kung Road, Section 2 Neihu

Taipei 114

Taiwan

Fax: +866-2-8792-7138

teinyu.chun@msa.hinet.net 